\title{
Carboxylated dithiafulvenes and tetrathiafulvalene vinylogues: synthesis, electronic properties, and complexation with zinc ions
}

\author{
Yunfei Wang and Yuming Zhao*
}

\author{
Full Research Paper \\ Address: \\ Department of Chemistry, Memorial University, St. John's, A1B 3X7, \\ NL, Canada \\ Email: \\ Yuming Zhao* - yuming@mun.ca \\ * Corresponding author \\ Keywords: \\ complexation; coordination polymers; porosity; redox activity; \\ tetrathiafulvalene
}

Open Access

\author{
Beilstein J. Org. Chem. 2015, 11, 957-965. \\ doi:10.3762/bjoc.11.107 \\ Received: 26 February 2015 \\ Accepted: 08 May 2015 \\ Published: 03 June 2015 \\ This article is part of the Thematic Series "Tetrathiafulvalene chemistry". \\ Guest Editor: P. J. Skabara \\ (C) 2015 Wang and Zhao; licensee Beilstein-Institut. \\ License and terms: see end of document.
}

\begin{abstract}
A class of carboxyl and carboxylate ester-substituted dithiafulvene (DTF) derivatives and tetrathiafulvalene vinylogues (TTFVs) has been synthesized and their electronic and electrochemical redox properties were characterized by UV-vis spectroscopic and cyclic voltammetric analyses. The carboxyl-TTFV was applied as a redox-active ligand to complex with $\mathrm{Zn}$ (II) ions, forming a stable Zn-TTFV coordination polymer. The structural, electrochemical, and thermal properties of the coordination polymer were investigated by infrared spectroscopy, cyclic voltammetry, powder X-ray diffraction, and differential scanning calorimetric analyses. Furthermore, the microscopic porosity and surface area of the Zn-TTFV coordination polymer were measured by nitrogen gas adsorption analysis, showing a BET surface of $148.2 \mathrm{~m}^{2} \mathrm{~g}^{-1}$ and an average pore diameter of $10.2 \mathrm{~nm}$.
\end{abstract}

\section{Introduction}

Tetrathiafulvalene (TTF) has been widely applied as a redoxactive building block in organic electronic materials and supramolecular assemblies [1-5], since the first discovery by Wudl and others in the early 1970s that TTF upon interactions with suitable electron acceptors could give rise to charge-transfer complexes exhibiting excellent metallic conductivity [6,7]. The remarkable electron-donating properties of TTF arise from its aromaticity-stabilized cationic states after releasing one and/or two electrons [1-5,8-10]. Tetrathiafulvalene vinylogues (TTFVs) are $\pi$-extended analogues of TTF bearing extended vinyl bridges between the two dithiole rings of TTF [9-11]. Similar to their parent TTF, TTFVs are excellent electron donors as well and they can undergo reversible electron transfers under mild redox conditions [11-15]. Of particular interest is the class of aryl-substituted TTFVs which show interesting conformational switching properties governed by redox processes [12,14-16]. For instance, the structure of diphenylated TTFV 1 can be transformed from a pseudo cis to a complete trans conformation upon oxidation (see Scheme 1). The application of TTFVs in material development began 
several decades ago, while the past few years have witnessed surging research activities on integrating TTFVs into a variety of $\pi$-conjugated molecular and macromolecular systems [12,1726]. In many of the studies, the remarkable redox activity and intriguing conformational switching properties of TTFVs were taken advantage of to enhance structural and electronic properties as well as to introduce some "intelligent" functions such as conformational switchability and selectivity in terms of molecular recognition and supramolecular interactions.

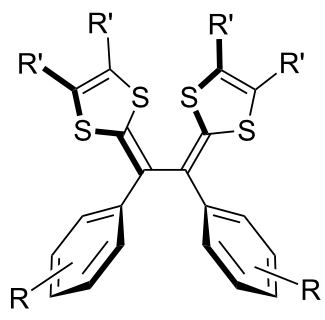

1

peudo cis

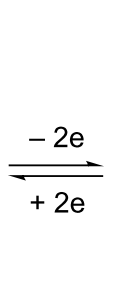

$\mathrm{R}$

$[1]^{2+}$
Scheme 1: Redox-induced conformational switching of diphenyl-TTFV 1.

The synthesis of TTFV structures is usually carried out through a facile iodine-promoted oxidative dimerization reaction of corresponding dithiafulvene (DTF) precursors [27]. This straightforward $\mathrm{C}-\mathrm{C}$ bond forming reaction has not only allowed TTFV derivatives with different substituents to be readily assembled, but served as an effective methodology to construct the $\pi$-conjugated frameworks of some TTFV-based macrocycles and polymers [12,28]. Previously, we have investigated a series of diphenyl-TTFVs with alkynyl groups attached to the phenyl units as synthetic building blocks, through which extension of $\pi$-conjugated structures could be conveniently executed via the $\mathrm{Pd}$-catalysed coupling and $\mathrm{Cu}$-catalysed alkyne-azide cycloaddition (i.e., click) reactions [22-26]. In this work, we continued to explore the class of carboxylated diphenyl-TTFVs, in view of the synthetic versatility of the carboxyl group towards various commonly used linkage groups (e.g., amides, esters). The carboxyl group also presents a reliable and useful ligand to coordinate with transition metal ions, which in turn provides easy access to novel organic-inorganic hybrid materials. The most notable example of research in this context is the recent development of metal organic frameworks (MOFs), wherein the design and synthesis of carboxyl functional ligands has played a pivotal role prompting the advancement of this field [29-31]. Very recently, some TTF-based ligands have been employed to achieve organic-inorganic hybrid materials with redox activity [32-35]; however, the use of TTFVs as ligands has not been reported in the literature prior to this work. This article thus describes the first exploration of the synthesis and properties of a carboxylated diphenyl-TTFV 6 (Scheme 2) and its ability to form new redox-active porous materials through the formation of coordination polymer with $\mathrm{Zn}$ (II) ions.<smiles>COC(=O)c1ccc(/C=C2\SC(C)=C(S(C)(=O)=O)S2)cc1</smiles>

(i) $\mathrm{NaOH}, \mathrm{MeOH} /$ $\mathrm{H}_{2} \mathrm{O}, 75^{\circ} \mathrm{C}$ overnight (ii) $\mathrm{HCl}(\mathrm{aq})$, rt $84 \%$ (i) $\mathrm{I}_{2}, \mathrm{CH}_{2} \mathrm{Cl}_{2}, \mathrm{rt}$
overnight

(ii) $\mathrm{Na}_{2} \mathrm{~S}_{2} \mathrm{O}_{3}$ (aq) $3 \mathrm{~h}, \mathrm{rt}, 80 \%$

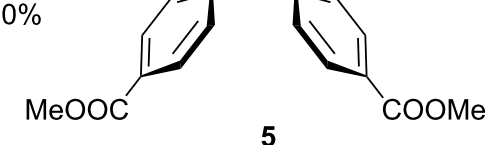

(i) $\mathrm{NaOH}, \mathrm{MeOH} /$ $\mathrm{H}_{2} \mathrm{O}, 75^{\circ} \mathrm{C}$
overnight<smiles>CSC1=C(C)SC(=Cc2ccc(C(=O)O)cc2)S1</smiles><smiles>CCCCS(C)(C)C</smiles>

Scheme 2: Synthesis of carboxylated TTFV 6 and DTF 7. 


\section{Results and Discussion}

The synthesis of carboxyl-TTFV 6 and its DTF precursor 7 was conducted via a route well established for aryl-substituted TTFV derivatives [22,23]. As shown in Scheme 2, thione 2 was first reacted with benzaldehyde 3 in the presence of trimethylphosphite at $105{ }^{\circ} \mathrm{C}$ [36]. This olefination reaction went completion within 3 hours to give DTF 4 in $77 \%$ yield after column separation. Compound $\mathbf{4}$ was then subjected to an oxidative dimerization in $\mathrm{CH}_{2} \mathrm{Cl}_{2}$ at room temperature using iodine as oxidant. The dimerization gave TTFV $\mathbf{5}$ as a stable yellow solid in $80 \%$ yield. Saponification was then performed on compound 5 in a solution of $\mathrm{NaOH}$ in water and methanol to finally afford carboxyl-TTFV 6 in 84\% yield. Compound 6 showed relatively poor solubility in non-polar organic solvents, but could be readily dissolved in polar solvents such as $\mathrm{MeOH}$, EtOH, THF, and DMSO. For comparison purposes, carboxylDTF 7 was also prepared by hydrolysis of DTF 4 using similar reaction conditions.

With carboxyl-TTFV 6 in hand, the preparation of coordination polymers with $\mathrm{Zn}$ (II) ions was undertaken. As outlined in Scheme 3, compound 6 was first mixed with two molar equivalents of $\mathrm{Zn}\left(\mathrm{NO}_{3}\right)_{2} \cdot 6 \mathrm{H}_{2} \mathrm{O}$ in $\mathrm{EtOH}$, and to this solution triethylamine was allowed to slowly diffuse in [37]. In a period of 4 days, coordination polymer $\mathbf{8}$ was gradually formed as a yellow coloured crystalline solid, which was insoluble in common solvents. By the same approach, complexes of carboxyl-DTF 7 with $\mathrm{Zn}$ (II) ions were also produced as a yellow powder.

The electronic properties of TTFVs $\mathbf{5}$ and $\mathbf{6}$ as well as their DTF precursors 4 and 7 were investigated by UV-vis absorption spectroscopy. Figure 1 shows the UV-vis absorption spectra of these compounds, in which the maximum absorption wavelengths $\left(\lambda_{\max }\right)$ of all the compounds appear to be nearly identical at ca. $385 \mathrm{~nm}$. There are, however, slight variations in the cut-off energies of long-wavelength absorption bands. The origins of these long-wavelength absorption bands are mainly due to HOMO to LUMO, HOMO to LUMO+1, and HOMO-1 to LUMO+1 transitions according to time-dependent density functional theory (TD-DFT) calculations (see the Supporting Information File 1 for details). The UV-vis data indicates that the degrees of $\pi$-delocalization for the TTFVs and DTF compounds are quite similar. This result is congruous with the fact that diphenyl-TTFVs generally prefer a twisted cisoid conformation in the ground state $[12,15,16]$, which in theory significantly disrupts the $\pi$-delocalization within the molecules. Therefore, even though the molecular sizes of TTFVs 5 and $\mathbf{6}$ are doubled in comparison with their DTF precursors $\mathbf{4}$ and $\mathbf{7}$, the degrees of $\pi$-electron delocalization in these molecules are still retained at a similar level in the ground state.

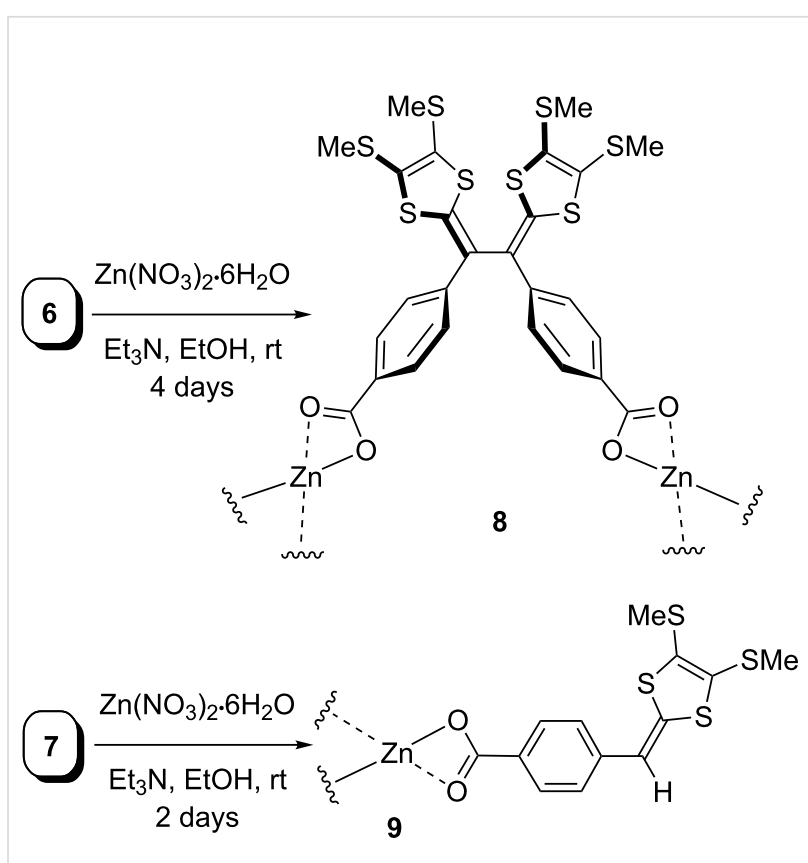

Scheme 3: Complexation of compounds 6 and 7 with $\mathrm{Zn}(\mathrm{II})$ ions.

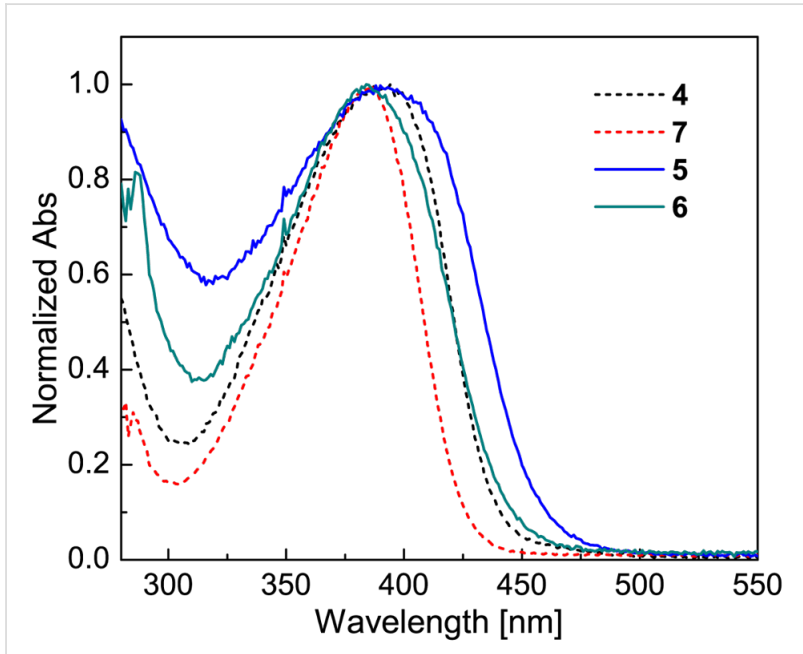

Figure 1: UV-vis spectra of TTFVs 5 and 6 (solid lines) and DTF 4 and 7 (dashed lines). Compounds 4 and 5 were measured in $\mathrm{CH}_{2} \mathrm{Cl}_{2}$, while compounds 6 and 7 were in THF.

The electrochemical redox properties of compounds 4-9 were characterized by cyclic voltammetry, and the detailed cyclic voltammograms are shown in Figure 2. For methyl esterappended DTF 4 (Figure 2A) an anodic peak was observed at $+0.82 \mathrm{~V}$ in the first cycle of scan, which is due to the singleelectron oxidation of the dithiole moiety into the dithiolium radical cation $[15,16]$. In the reverse scan, a cathodic peak emerged at $+0.54 \mathrm{~V}$ which is assigned to the bielectronic reduction of the TTFV product electrochemically generated on the 

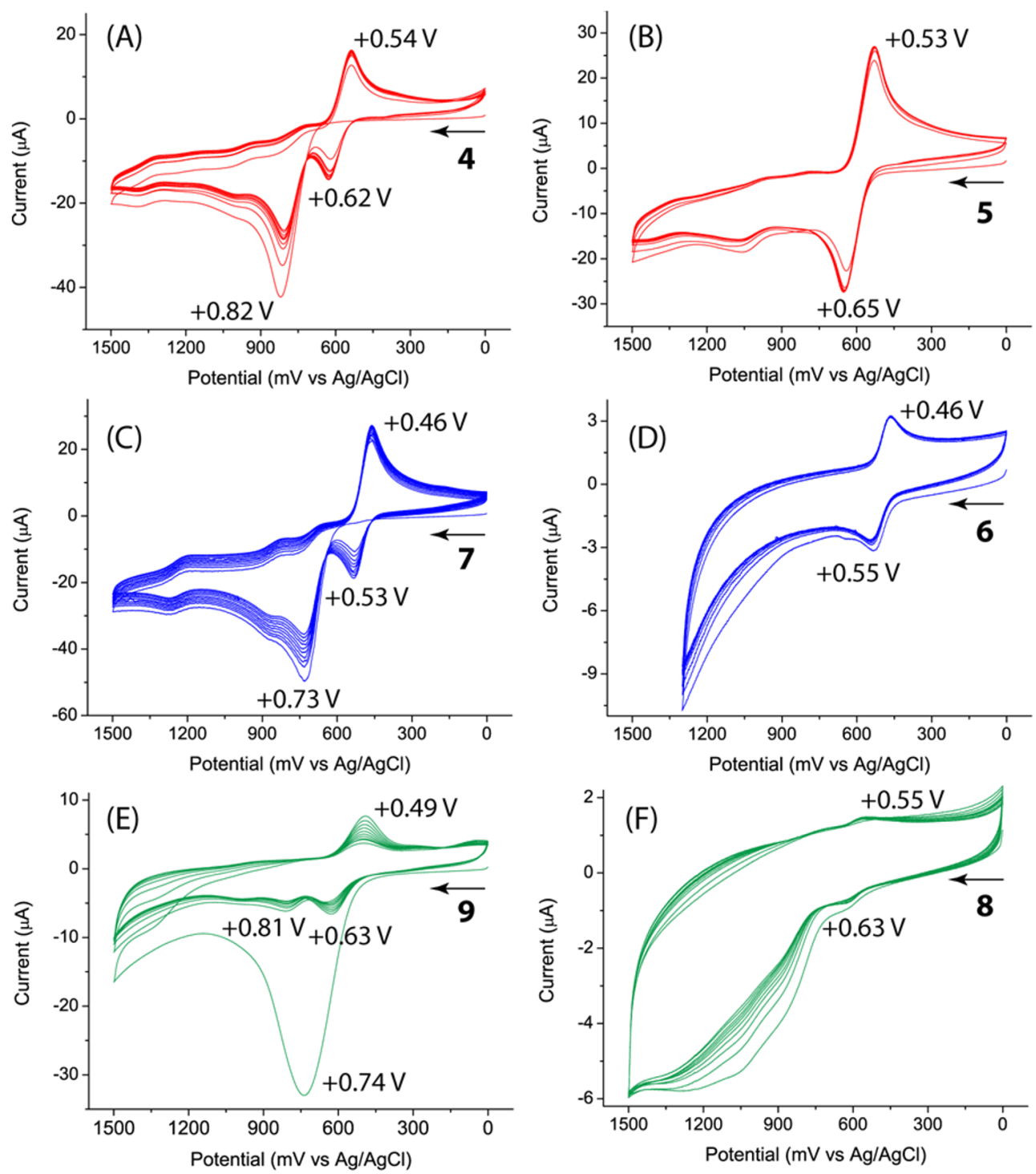

Figure 2: Cyclic voltammograms of compounds 4-9. Experimental conditions: supporting electrolyte: $\mathrm{Bu}_{4} \mathrm{NBF}_{4}(0.1 \mathrm{M})$, working electrode: glassy carbon, counter electrode: Pt wire, reference electrode: $\mathrm{Ag} / \mathrm{AgCl}(3 \mathrm{M} \mathrm{NaCl})$, scan rate: $200 \mathrm{mV} \mathrm{s}^{-1}$. Compounds 4 (1.5 mM), 5 (0.73 mM), 8 , and 9 were measured in $\mathrm{CH}_{2} \mathrm{Cl}_{2}$. Compounds $6(0.76 \mathrm{mM})$ and $7(1.5 \mathrm{mM})$ were measured in $\mathrm{CH}_{3} \mathrm{CN}$.

electrode surface via the DTF dimerization reaction $[15,16]$. In the following scan cycles, the redox wave pair characteristic of TTFV at $E_{\mathrm{pa}}=+0.62 \mathrm{~V}$ and $E_{\mathrm{pc}}=+0.54 \mathrm{~V}$ was found to gradually increase in intensity as a result of increasing electrochemical dimerization. The same electrochemical patterns can be seen in the cyclic voltammograms of carboxyl-DTF 7 and Zn-DTF complex 9 (Figure 2C and 2E); however, their redox potentials showed a slight degree of variation. Experimentally, the cyclic voltammogram of $\mathbf{9}$ was determined from its solid thin film compressed on the working electrode surface. It is interesting to note that Zn-DTF complex 9 retained the redox activity and electrochemical reactivity of DTF even in the solid state. The cyclic voltammograms of compounds 5 and $\mathbf{6}$ both featured a reversible redox wave pair due to the simultaneous bielectronic transfers occurring at the TTFV moieties (Figure 2B and 2D). In the cyclic voltammogram of Zn-TTFV coordination polymer $\mathbf{8}$ (measured from a solid film prepared in the same way as 9), the redox wave pair of TTFV is discernible but much weaker than that of Zn-DTF 9 (Figure 2F), suggesting that the electrochemical activity of the coordination polymer is considerably reduced in comparison with the smaller-sized Zn-DTF complex.

The structural properties of Zn-TTFV coordination polymer $\mathbf{8}$ and Zn-DTF complex 9 were examined by IR spectroscopy (Figure 3). Compared with the IR spectra of carboxyl-TTFV 6 


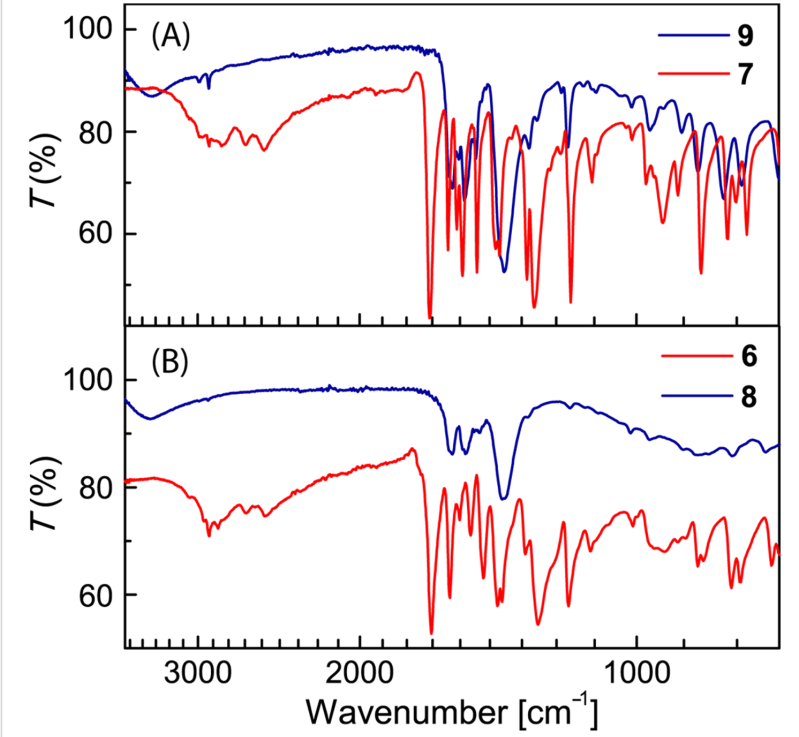

Figure 3: FTIR spectra of compounds 6-9.

and carboxyl-DTF 7, the vibrational bands of free carboxyl groups were clearly absent in the spectra of $\mathbf{8}$ and $\mathbf{9}$, confirming that the carboxyl groups were completely coordinated with $\mathrm{Zn}$ (II) ions. The crystalline properties of coordination polymer 8 were examined by powder X-ray diffraction (PXRD) analysis. The diffraction patterns shown in Figure 4 confirm that coordinate polymer 8 possesses crystallinity in the solid state. Actually, the diffraction patterns were found to bear resemblance to those of zincite $\mathrm{ZnO}$. Such crystalline features hence point to a possibility of the coordination polymer to take some kind of framework-like structures in the solid state with certain microscopic porosity.

To assess the porous properties of Zn-TTFV 8, nitrogen gas adsorption analysis was conducted at $77 \mathrm{~K}$. The adsorption isotherm shown in Figure 5A indicates a Type-II adsorption behaviour. Application of the Brunauer-Emmett-Teller (BET) model gave a BET surface area of $148.2 \mathrm{~m}^{2} \mathrm{~g}^{-1}$ and an adsorption average pore diameter of $10.2 \mathrm{~nm}$. The pore size distribution analysis data revealed that Zn-TTFV coordination polymer 8 carried microporosity primarily in the range of tens of nanometers. Scanning electron microscopic (SEM) imaging was performed on the particles of $\mathbf{8}$ to show some kind of crystalline-like micromorphology. In line with the gas adsorption results, there were no relatively large pores on the micron scale observable in the particles (see the inset of Figure 5B). On the submicron scale, however, corrugated microporous features could be clearly observed (see Figure 5B). To understand the origin of the micropores, nitrogen gas adsorption experiments were performed on Zn-DTF complex 9. The experimental

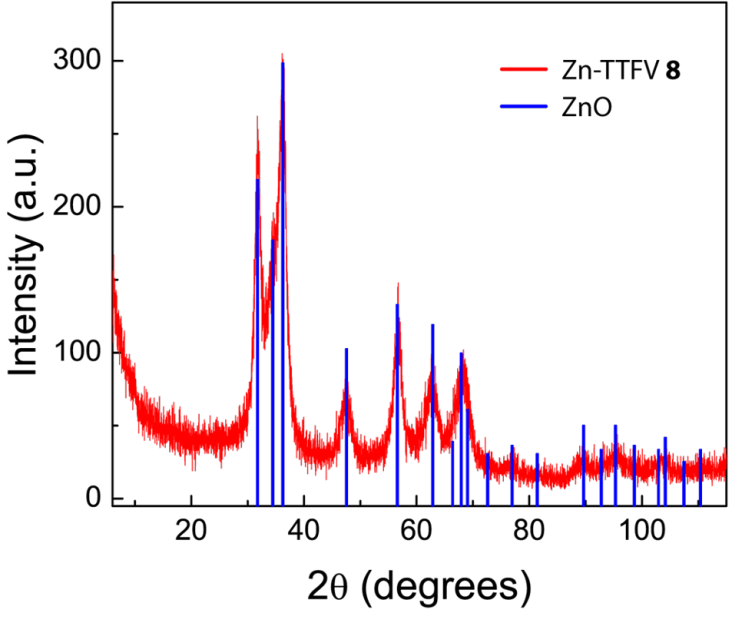

Figure 4: PXRD patterns of the Zn-TTFV coordination polymer 8 (red line) in comparison with the diffraction data of zincite $\mathrm{ZnO}$ (blue bars).
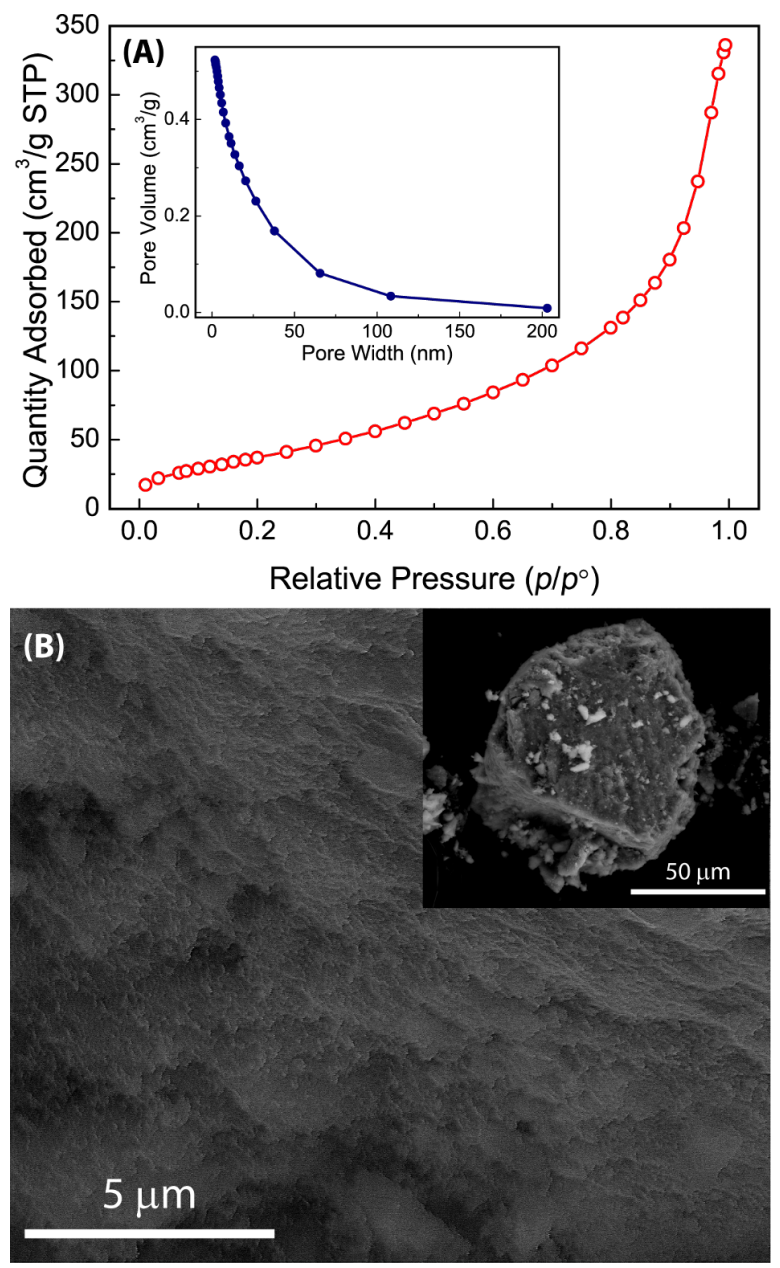

Figure 5: (A) Nitrogen adsorption isotherm of coordination polymer 8 measured at $77 \mathrm{~K}$. Inset: pore size distributions. (B) SEM image of the powder of 8. 
results did not lead to any meaningful measurements of BET surface area and microporosity, indicating a lack of porous structures in the solid of $\mathbf{9}$. The major structural difference between Zn-DTF 9 and Zn-TTFV 8 is that $\mathbf{8}$ assumes crystalline polymeric frameworks as evidenced by PXRD analysis, whereas 9 is in the form of small clusters and amorphous (see Figure S10 in Supporting Information File 1 for the detailed PXRD data of 9). It is therefore reasonable to propose that the microporosity in $\mathbf{8}$ is directly related to the coordination polymer structure.

Finally, the thermal stability of coordination polymer $\mathbf{8}$ and Zn-DTF 9 were evaluated by differential scanning calorimetric (DSC) analysis, and detailed DSC traces are illustrated in Figure 6. The DSC data of Zn-TTFV 8 (Figure 6A) manifested very good thermal stability up to $400{ }^{\circ} \mathrm{C}$, without any significant melting or decomposition except a slight phase transition at $272{ }^{\circ} \mathrm{C}$. Comparatively, the DSC trace of carboxyl-TTFV ligand 6 showed a distinctive melting process at $317^{\circ} \mathrm{C}$, which was immediately followed by a prominent sharp exothermic peak at $326^{\circ} \mathrm{C}$ (Figure 6B). The exothermic process is possibly due to a chemical reaction(s); however, the exact reactivity awaits further investigation to clearly elucidate. Zn-DTF 9 gave a moderate endothermic peak at $152{ }^{\circ} \mathrm{C}$ and a significant exothermic peak at $358{ }^{\circ} \mathrm{C}$ (Figure 6C). For carboxyl-DTF 7, a notable melting point was observed at $199{ }^{\circ} \mathrm{C}$, and the melting was followed by certain exothermic processes in the range of 200 to $285^{\circ} \mathrm{C}$. The DSC results indicated that the formation of $\mathrm{Zn}$-TTFV coordinate polymer could give rise to considerably improved thermal stability, a property particularly beneficial for practical device and material applications.

\section{Conclusion}

In summary, we have synthesized carboxylated diphenyl-TTFV 6 and phenyl-DTF 7 as redox-active ligands to complex with $\mathrm{Zn}$ (II) ions. The electronic and electrochemical properties of the TTFV and DTF compounds were found to be in line with other related TTFV and DTF derivatives. Of great interest is that the complexes with $\mathrm{Zn}$ (II) ions retain the redox activity and electrochemical reactivity of their TTFV and DTF ligands in the solid state. Another significant added value is the thermal robustness of the Zn-TTFV coordination polymer. Collectively, the good electrochemical and thermal properties point to a promising prospect for them to be further developed into practically useful organic-inorganic hybrid materials through the coordination polymer approach. The Zn-TTFV coordination polymer was also found to be crystalline in nature. At this stage, meaningful single-crystal diffraction data has not yet been successfully determined. Without such data clear understanding of the detailed solid-state structural properties cannot be established.
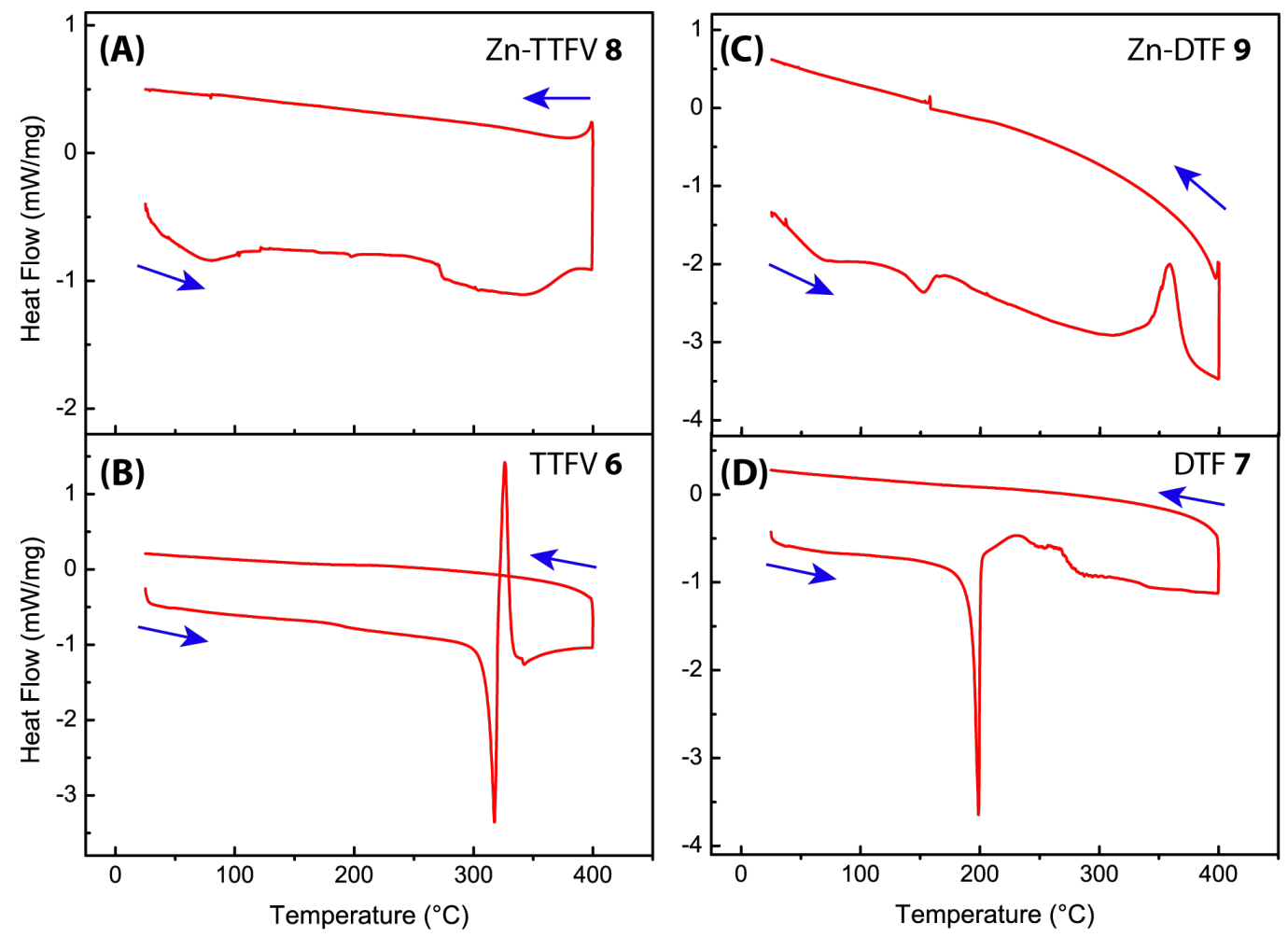

Figure 6: DSC traces of compounds 6-9 measured under a nitrogen atmosphere. Scan range: $25-400{ }^{\circ} \mathrm{C}$, scan rate: $10^{\circ} \mathrm{C}$ min ${ }^{-1}$. 
Our future work is moving towards tuning the side groups of the TTFV ligand to produce $\mathrm{Zn}$ complexes with better crystallinity. Finally, the Zn-TTFV coordination polymer exhibited significant microporosity and surface area. Overall, our current studies have cast a light on the fundamental redox and solidstate properties of the class of TTFV-based organic-inorganic hybrid materials, and the findings disclosed in this article should offer useful guidance to further material design and development.

\section{Experimental}

Chemicals were purchased from commercial suppliers and used directly without purification. All reactions were conducted in standard, dry glassware and under an inert atmosphere of nitrogen unless otherwise noted. Evaporation and concentration were carried out with a water-aspirator. Flash column chromatography was performed with silica gel 60 (240-400 mesh). Thin-layer chromatography (TLC) was carried out with silica gel F254 covered on plastic sheets and visualized by UV light. Melting points were measured on a SRS OptiMelt melting point apparatus. ${ }^{1} \mathrm{H}$ and ${ }^{13} \mathrm{C}$ NMR spectra were measured on a Bruker Avance III $300 \mathrm{MHz}$ multinuclear spectrometer. Chemical shifts $(\delta)$ are reported in ppm downfield relative to the signal of the internal reference $\mathrm{SiMe}_{4}$. Coupling constants $(J)$ are given in Hz. Infrared spectra (IR) were recorded on a Bruker Alfa spectrometer. HRMS analyses were performed on an Agilent 6230 TOF LC/MS instrument using an APPI ionizer. UV-vis absorption spectra were measured on a Cary 6000i spectrophotometer. Cyclic voltammetric analyses were carried out in a standard three-electrode setup controlled by a BASi epsilon workstation. Differential scanning calorimetric (DSC) analyses were performed on a Mettler-Toledo DSC1 calorimeter. Powder X-ray diffraction (PXRD) data was collected on a Rigaku Ultima IV diffractometer equipped with a copper X-ray source with a wavelength of $1.54 \mathrm{~nm}$. Scanning electron microscopy (SEM) was performed on an FEI MLA 650 FEG microscope. BET surface area and pore size analyses were performed on a Micromeritics TriStar II Plus instrument. The degassing was done on a Flow Prep 060 instrument. The calculations were carried out with the MicroActive for TriStar II Plus software (Version 2.02). Thione 2 was prepared according to the procedures we reported previously $[22,23]$.

DTF 4: A mixture of methyl 4-formylbenzoate $(3,1.83 \mathrm{~g}$, $11.1 \mathrm{mmol})$ and thione $2(3.03 \mathrm{~g}, 13.4 \mathrm{mmol})$ in $\mathrm{P}(\mathrm{OMe})_{3}$ $(100 \mathrm{~mL})$ was stirred and heated at $105{ }^{\circ} \mathrm{C}$ for $3 \mathrm{~h}$. The excess $\mathrm{P}(\mathrm{OMe})_{3}$ was removed by vacuum distillation. The residue was purified by silica column chromatography (EtOAc/hexanes, 1:9) to afford compound DTF 4 (2.93 g, $8.55 \mathrm{mmol}, 77 \%)$ as a yellow crystalline solid. mp 88.6-90.9 ${ }^{\circ} \mathrm{C} ;{ }^{1} \mathrm{H}$ NMR $(300 \mathrm{MHz}$, $\left.\mathrm{CDCl}_{3}\right) \delta 8.01(\mathrm{~d}, J=8.4 \mathrm{~Hz}, 2 \mathrm{H}), 7.25(\mathrm{~d}, J=8.3 \mathrm{~Hz}, 2 \mathrm{H})$, $6.51(\mathrm{~s}, 1 \mathrm{H}), 3.91(\mathrm{~s}, 3 \mathrm{H}), 2.44(\mathrm{~d}, J=2.8 \mathrm{~Hz}, 6 \mathrm{H}) \mathrm{ppm}$; ${ }^{13} \mathrm{C}$ NMR $\left(75 \mathrm{MHz}, \mathrm{CDCl}_{3}\right) \delta 166.8,140.5,136.2,129.9$, 127.9, 126.7, 126.3, 124.5, 113.3, 52.0, 19.0, 18.9 ppm; FTIR (neat): 2914, 1704, 1599, 1567, 1545, 1492, 1422, 1265, 1175, 1096, 851, 798, 693, $470 \mathrm{~cm}^{-1}$; APPI-HRMS $(\mathrm{m} / \mathrm{z}$, positive mode): $\left[\mathrm{M}^{+}\right]$calcd for $\mathrm{C}_{14} \mathrm{H}_{14} \mathrm{O}_{2} \mathrm{~S}_{4}, 341.9877$; found, 341.9878 .

TTFV 5: A mixture of DTF $4(0.25 \mathrm{~g}, 0.73 \mathrm{mmol})$ and $I_{2}$ (0.55 g, $2.2 \mathrm{mmol})$ in $\mathrm{CH}_{2} \mathrm{Cl}_{2}(100 \mathrm{~mL})$ was stirred at $\mathrm{rt}$ overnight. Then a satd $\mathrm{Na}_{2} \mathrm{~S}_{2} \mathrm{O}_{3}$ solution (aq, $90 \mathrm{~mL}$ ) was added. The mixture was stirred for another $3 \mathrm{~h}$ at rt. The organic layer was separated, washed with $\mathrm{H}_{2} \mathrm{O}$, dried over $\mathrm{MgSO}_{4}$, and concentrated under vacuum. The residue was purified by silica column chromatography (EtOAc/hexanes, 1:4) to afford compound $5(0.20 \mathrm{~g}, 0.29 \mathrm{mmol}, 80 \%)$ as a yellow solid. mp 183.9-185.4 ${ }^{\circ} \mathrm{C}$; ${ }^{1} \mathrm{H}$ NMR $\left(300 \mathrm{MHz}, \mathrm{CDCl}_{3}\right) \delta 7.97$ (d, $J=8.7 \mathrm{~Hz}, 4 \mathrm{H}), 7.46(\mathrm{~d}, J=8.7 \mathrm{~Hz}, 4 \mathrm{H}), 3.89(\mathrm{~s}, 6 \mathrm{H}), 2.44(\mathrm{~s}$, $6 \mathrm{H}), 2.38(\mathrm{~s}, 6 \mathrm{H}) \mathrm{ppm} ;{ }^{13} \mathrm{C} \mathrm{NMR}\left(75 \mathrm{MHz}, \mathrm{CDCl}_{3}\right) \delta 166.6$, $141.1,140.3,130.1,129.1,127.9,126.1,125.5,122.9,52.0$, 18.9, 18.8 ppm; FTIR (neat): 2942, 2918, 1709, 1600, 1519, $1473,1430,1273,1182,1107,766,713,465 \mathrm{~cm}^{-1}$; APPI-HRMS $\left(\mathrm{m} / \mathrm{z}\right.$, positive mode): $\left[\mathrm{M}^{+}\right]$calcd for $\mathrm{C}_{28} \mathrm{H}_{26} \mathrm{O}_{4} \mathrm{~S}_{8}$, 681.9597; found, 681.9584.

Carboxylated TTFV 6: A mixture of TTFV 5 (50.0 mg, $0.0732 \mathrm{mmol}$ ) and $\mathrm{NaOH}(46.9 \mathrm{mg}, 1.17 \mathrm{mmol})$ in $\mathrm{MeOH} / \mathrm{H}_{2} \mathrm{O}$ (40 mL, 3:1) was stirred at $75^{\circ} \mathrm{C}$ overnight. The solvent $\mathrm{MeOH}$ was removed under vacuum, and the residue was diluted to $50 \mathrm{~mL}$ with $\mathrm{H}_{2} \mathrm{O}$ and acidified to $\mathrm{pH} 4$ with $\mathrm{HCl}$ (aq). The precipitate formed was extracted with EtOAc, washed with $\mathrm{H}_{2} \mathrm{O}$, dried over $\mathrm{MgSO}_{4}$, and concentrated under vacuum to afford compound 6 (40.3 $\mathrm{mg}, 0.0615 \mathrm{mmol}, 84 \%)$ as a yellow solid. mp 292.9-295.7 ${ }^{\circ} \mathrm{C}$; ${ }^{1} \mathrm{H}$ NMR (300 MHz, DMSO- $\left.d_{6}\right) \delta$ $7.94(\mathrm{~d}, J=8.5 \mathrm{~Hz}, 4 \mathrm{H}), 7.48(\mathrm{~d}, J=8.4 \mathrm{~Hz}, 4 \mathrm{H}), 2.48(\mathrm{~s}, 6 \mathrm{H})$, $2.40(\mathrm{~s}, 6 \mathrm{H}) \mathrm{ppm} ;{ }^{13} \mathrm{C} \mathrm{NMR}\left(75 \mathrm{MHz}, \mathrm{DMSO}-d_{6}\right) \delta 166.7$, $140.0,139.1,130.0,128.8,126.8,125.9,125.1,122.7,18.2$, 18.2 ppm; FTIR (neat): 2916-2536 (br), 1672, 1596, 1515, 1467, 1416, 1280, 1186, 789, 541, $469 \mathrm{~cm}^{-1}$; APPI-HRMS ( $m / z$, negative mode) $\left[\mathrm{M}^{-}\right]$calcd for $\mathrm{C}_{26} \mathrm{H}_{22} \mathrm{O}_{4} \mathrm{~S}_{8}, 653.9284$; found, 653.9293 .

Carboxylated DTF 7: A mixture of DTF 4 (0.30 g, $0.88 \mathrm{mmol})$ and $\mathrm{NaOH}(0.56 \mathrm{~g}, 14 \mathrm{mmol})$ in $\mathrm{MeOH} / \mathrm{H}_{2} \mathrm{O}(240 \mathrm{~mL}, 3: 1)$ was stirred at $75{ }^{\circ} \mathrm{C}$ overnight. The solvent $\mathrm{MeOH}$ was removed under vacuum, and the residue was diluted to $100 \mathrm{~mL}$ with $\mathrm{H}_{2} \mathrm{O}$ and acidified to $\mathrm{pH} 4$ with $\mathrm{HCl}$ (aq). The precipitate formed was subjected to suction filtration to afford compound $7(0.24 \mathrm{~g}, 0.73 \mathrm{mmol}, 84 \%)$ as a yellow solid. mp 191.0-193.2 ${ }^{\circ} \mathrm{C} ;{ }^{1} \mathrm{H}$ NMR (300 MHz, DMSO- $d_{6}$ ) $\delta 12.86$ (s, 1H), $7.94(\mathrm{~d}, J=8.4 \mathrm{~Hz}, 2 \mathrm{H}), 7.32(\mathrm{~d}, J=8.3 \mathrm{~Hz}, 2 \mathrm{H}), 6.82$ 
$(\mathrm{s}, 1 \mathrm{H}), 2.47(\mathrm{~s}, 3 \mathrm{H}), 2.45(\mathrm{~s}, 3 \mathrm{H}) \mathrm{ppm} ;{ }^{13} \mathrm{C} \mathrm{NMR}(75 \mathrm{MHz}$, DMSO- $\left.d_{6}\right) \delta 166.9,139.7,134.6,129.7,127.4,127.3,126.3$, 122.7, 113.7, 18.3, 18.1 ppm; FTIR (neat): 2914-2540 (br), 1677, 1602, 1567, 1545, 1490, 1408, 1291, 1178, 850, 796, 505, $470 \mathrm{~cm}^{-1}$; APPI-HRMS ( $\mathrm{m} / \mathrm{z}$, negative mode) $\left[\mathrm{M}^{-}\right]$calcd for $\mathrm{C}_{13} \mathrm{H}_{12} \mathrm{O}_{2} \mathrm{~S}_{4}$, 327.9720; found, 327.9727 .

Zn-TTFV 8: A solution of TTFV $6(0.12 \mathrm{~g}, 0.18 \mathrm{mmol})$ and $\mathrm{Zn}\left(\mathrm{NO}_{3}\right)_{2} \cdot 6 \mathrm{H}_{2} \mathrm{O}(0.11 \mathrm{~g}, 0.37 \mathrm{mmol})$ in $\mathrm{EtOH}(350 \mathrm{~mL})$ was added into a beaker, which was placed in a larger beaker containing $\mathrm{Et}_{3} \mathrm{~N} / \mathrm{EtOH}(40 \mathrm{~mL}, 1: 1)$. The larger beaker was sealed and left standing for 4 days. The precipitate formed within the smaller beaker was collected by centrifugation and rinsed with EtOH to afford Zn-TTFV $8(50.8 \mathrm{mg})$ as a yellow solid. FTIR (neat): $3381,1586,1535,1400,857,787 \mathrm{~cm}^{-1}$.

Zn-DTF 9: A solution of DTF 7 (20.0 $\mathrm{mg}, 0.0610 \mathrm{mmol})$ and $\mathrm{Zn}\left(\mathrm{NO}_{3}\right)_{2} \cdot 6 \mathrm{H}_{2} \mathrm{O}(21.8 \mathrm{mg}, 0.0733 \mathrm{mmol})$ in EtOH $(40 \mathrm{~mL})$ was added into a vial, which was placed in a jar containing $\mathrm{Et}_{3} \mathrm{~N} / \mathrm{EtOH}$ (6 mL, 1:2). The jar was sealed and left standing for 2 days. The precipitate formed in the vial was collected by centrifugation and rinsed with EtOH to afford Zn-DTF 9 (15.1 mg) as a yellow solid. FTIR (neat): 3360, 2990, 2916, $1585,1559,1538,1494,1392,1187,803,768,472 \mathrm{~cm}^{-1}$.

\section{Supporting Information}

\section{Supporting Information File 1 \\ ${ }^{1} \mathrm{H}$ and ${ }^{13} \mathrm{C}$ NMR spectra of compounds 4-7, PXRD data of $\mathbf{8}$ and $\mathbf{9}$, thermal gravimetric analysis (TGA) data of $\mathbf{8}$, and time-dependent (TD) DFT calculation results for compounds 6 and 7. \\ [http://www.beilstein-journals.org/bjoc/content/ supplementary/1860-5397-11-107-S1.pdf]}

\section{Acknowledgements}

We thank the Natural Sciences and Engineering Research Council (NSERC) of Canada, Canada Foundation for Innovation (CFI), and Memorial University for financial support.

\section{References}

1. Yamada, J.-i.; Sugimoto, T. TTF Chemistry: Fundamentals and Applications of Tetrathiafulvalene; Springer: Berlin, Germany, 2004.

2. Segura, J. L.; Martín, N. Angew. Chem., Int. Ed. 2001, 40, 1372-1409. doi:10.1002/1521-3773(20010417)40:8<1372::AID-ANIE1372>3.0.CO; 2-I

3. Simonsen, K. B.; Becher, J. Synlett 1997, 1211-1220. doi:10.1055/s-1997-1001

4. Nielsen, M. B.; Lomholt, C.; Becher, J. Chem. Soc. Rev. 2000, 29, 153-164. doi:10.1039/A803992E
5. Canevet, D.; Sallé, M.; Zhang, G.; Zhang, D.; Zhu, D. Chem. Commun. 2009, 2245-2269. doi:10.1039/B818607N

6. Wudl, F.; Wobschall, D.; Hufnagel, E. J. J. Am. Chem. Soc. 1972, 94 , 670-672. doi:10.1021/ja00757a079

7. Ferraris, J.; Cowan, D. O.; Walatka, V.; Perlstein, J. H. J. Am. Chem. Soc. 1973, 95, 948-949. doi:10.1021/ja00784a066

8. VandeVondele, J.; Lynden-Bell, R.; Meijer, E. J.; Sprik, M. J. Phys. Chem. B 2005, 110, 3614-3623. doi:10.1021/jp054841+

9. Nielsen, M. B.; Sauer, S. P. A. Chem. Phys. Lett. 2008, 453, 136-139. doi:10.1016/j.cplett.2008.01.012

10. Bendikov, M.; Wudl, F.; Perepichka, D. F. Chem. Rev. 2004, 104, 4891-4946. doi:10.1021/cr030666m

11. Frère, P.; Skabara, P. J. Chem. Soc. Rev. 2005, 34, 69-98. doi:10.1039/B316392J

12. Zhao, Y. M.; Chen, G.; Mulla, K.; Mahmud, I.; Liang, S.; Dongare, P.; Thompson, D. W.; Dawe, L. N.; Bouzan, S. Pure Appl. Chem. 2012, 84, 1005-1025. doi:10.1351/Pac-Con-11-09-22

13. Roncali, J. J. Mater. Chem. 1997, 7, 2307-2321. doi:10.1039/A703956E

14. Bryce, M. R.; Coffin, M. A.; Clegg, W. J. Org. Chem. 1992, 57, 1696-1699. doi:10.1021/jo00032a018

15. Carlier, R.; Hapiot, P.; Lorcy, D.; Robert, A.; Tallec, A. Electrochim. Acta 2001, 46, 3269-3277. doi:10.1016/S0013-4686(01)00619-3

16. Bellec, N.; Boubekeur, K.; Carlier, R.; Hapiot, P.; Lorcy, D.; Tallec, A. J. Phys. Chem. A 2000, 104, 9750-9759. doi:10.1021/jp001326x

17. Lorcy, D.; Guerro, M.; Bergamini, J.-F.; Hapiot, P. J. Phys. Chem. B 2013, 117, 5188-5194. doi:10.1021/jp401537a

18. Gontier, E.; Bellec, N.; Brignou, P.; Gohier, A.; Guerro, M.; Roisnel, T.; Lorcy, D. Org. Lett. 2010, 12, 2386-2389. doi:10.1021/ol1007422

19. Liang, S.; Zhao, Y.; Adronov, A. J. Am. Chem. Soc. 2013, 136, 970-977. doi:10.1021/ja409918n

20. Liang, S.; Chen, G.; Zhao, Y. J. Mater. Chem. C 2013, 1, 5477-5490. doi:10.1039/C3TC30317A

21. Liang, S.; Chen, G.; Peddle, J.; Zhao, Y. Chem. Commun. 2012, 48, 3100-3102. doi:10.1039/C2CC17935K

22. Chen, G.; Mahmud, I.; Dawe, L. N.; Daniels, L. M.; Zhao, Y. J. Org. Chem. 2011, 76, 2701-2715. doi:10.1021/jo2000447

23. Chen, G.; Mahmud, I.; Dawe, L. N.; Zhao, Y. Org. Lett. 2010, 12, 704-707. doi:10.1021/ol9026683

24. Chen, G.; Zhao, Y. Org. Lett. 2014, 16, 668-671. doi:10.1021/ol403295q

25. Mulla, K.; Shaik, H.; Thompson, D. W.; Zhao, Y. Org. Lett. 2013, 15, 4532-4535. doi:10.1021/ol402093a

26. Mulla, K.; Dongare, P.; Thompson, D. W.; Zhao, Y. Org. Biomol. Chem. 2012, 10, 2542-2544. doi:10.1039/C2OB06828A

27. Hapiot, P.; Lorcy, D.; Tallec, A.; Carlier, R.; Robert, A. J. Phys. Chem. 1996, 100, 14823-14827. doi:10.1021/jp961048v

28. Inagi, S.; Naka, K.; Chujo, Y. J. Mater. Chem. 2007, 17, 4122-4135. doi:10.1039/B708640G

29. Eddaoudi, M.; Kim, J.; Rosi, N.; Vodak, D.; Wachter, J.; O'Keeffe, M.; Yaghi, O. M. Science 2002, 295, 469-472. doi:10.1126/science. 1067208

30. Cook, T. R.; Zheng, Y.-R.; Stang, P. J. Chem. Rev. 2013, 113, 734-777. doi:10.1021/cr3002824

31. MacGillivray, L. Metal-Organic Frameworks: Design and Application; Wiley \& Sons: Hoboken, NJ, USA, 2010.

32. Chen, B.; Lv, Z.-P.; Leong, C. F.; Zhao, Y.; D'Alessandro, D. M.; Zuo, J.-L. Cryst. Growth Des. 2015, 15, 1861-1870. doi:10.1021/acs.cgd.5b00014 
33. Zhu, Q.-Y.; Wang, J.-P.; Qin, Y.-R.; Shi, Z.; Han, Q.-H.; Bian, G.-Q.;

Dai, J. Dalton Trans. 2011, 40, 1977-1983. doi:10.1039/CODT01152E

34. Ding, Y.; Chen, Q.; Zhong, J.-C.; Munakata, M.; Konaka, H.;

Ning, G.-L.; Wang, H.-Z. Polyhedron 2008, 27, 1393-1400.

doi:10.1016/j.poly.2008.01.010

35. Martínez, V.; Gaspar, A. B.; Muñoz, M. C.; Ballesteros, R.;

Ortega-Villar, N.; Ugalde-Saldívar, V. M.; Moreno-Esparza, R.;

Real, J. A. Eur. J. Inorg. Chem. 2009, 303-310.

doi:10.1002/ejic.200800988

36. Christensen, C. A.; Batsanov, A. S.; Bryce, M. R. J. Org. Chem. 2007, 72, 1301-1308. doi:10.1021/jo062199p

37. Kim, J.; Chen, B.; Reineke, T. M.; Li, H.; Eddaoudi, M.; Moler, D. B.; O'Keeffe, M.; Yaghi, O. M. J. Am. Chem. Soc. 2001, 123, 8239-8247. doi:10.1021/ja010825o

\section{License and Terms}

This is an Open Access article under the terms of the Creative Commons Attribution License

(http://creativecommons.org/licenses/by/2.0), which permits unrestricted use, distribution, and reproduction in any medium, provided the original work is properly cited.

The license is subject to the Beilstein Journal of Organic Chemistry terms and conditions:

(http://www.beilstein-journals.org/bjoc)

The definitive version of this article is the electronic one which can be found at: doi:10.3762/bjoc. 11.107 